\title{
Students Are Literate but They Do Not Read
}

\author{
Jackson Toby
}

Students admitted to American colleges are usually literate, but that does not mean that they habitually read books of any kind. Mason Gross, late president of Rutgers University, was well aware of this pedagogical challenge. He explained in a lecture to new faculty an advantage he found in teaching philosophy at Rutgers rather than at Harvard or Princeton. At Rutgers he was more likely to be teaching the ideas of Plato and Aristotle to youngsters who would not recognize their names. Rutgers students are more likely to be the first in their family to go to college; they are less likely to come from homes containing bookcases from which a book could be taken out and examined. They may never have seen one of their parents reading a book. President Gross was putting an optimistic gloss on the disadvantage of teaching students who are literate but never have read any fiction or nonfiction book in its entirety. Exciting though it may be to awaken enthusiasm for Plato and Aristotle in students who never heard of them before, that is less likely than grudging acquiescence to doing reading assignments. Any new experience suffers from the handicap of being first; it has to compete for attention with experiences that one has chosen and rechosen many times, like the reinforced satisfaction that tennis or cards may have already provided.

Nevertheless, the first experience makes the second more thinkable and therefore more doable. While some literate students attend college and even graduate without becoming voluntary book readers, others are stimulated by the enthusiastic recommendations of professors like President Gross who reinforce the notion of picking up a book and actually reading it completely. Psychologists are well aware of the power of external reinforcement to motivate behavior. Harvard psychology professor B.F. Skinner demonstrated that the external reinforcement of corn pellets can teach surprisingly

Jackson Toby is professor emeritus of sociology at Rutgers University, where he was director of the Institute for Criminological Research; jtoby@scarletmail.rutgers.edu. His latest book is: The Lowering of Higher Education in America (Praeger 2009). 
unnatural pecking habits to pigeons by rewarding actions he wanted them to learn. Although pigeons stumbled on the action, memory of the reward led first to one repetition, which was rewarded again, and further imbedded in their habit repertoire with each additional repetition. Reading a book, however, is more complicated than pecking. Although the brains of human beings are only marginally different from the brains of pigeons, the minds of human beings are vastly different from anything that goes on in the brains of pigeons. Stanford University psychology professor, Albert Bandura, pointed to the mind's ability to "self-reinforce" an idea or experience. Self-reinforcement is more helpful than external reinforcement in explaining why some students choose to become readers of books and others don't. Thus, when President Gross lectured to his students about Socratic dialogues in Plato's Republic, some students chose to read The Republic themselves, thought about the experience, and choose to read another book. As far as is known, pigeons are incapable of thinking about the merits of corn pellets.

The human mind can self-reinforce every first experience in memory and thereby make the second more likely. For instance, applying for and getting the first job makes an employee more likely to imagine getting another job if the first is not working out. Self-reinforcement also explains why more residential burglaries take place in the low-income neighborhoods where the burglars live rather than in high-income neighborhoods that are more likely to contain valuables worth stealing. In short, self-reinforcement of the first experience paves the way for the second-for better or worse. In the cases of the first cigarette, the first drink, and the first exposure to opiates, it may be for the worse. Selfreinforcement is necessary for human beings to develop alcohol or drug addiction. Apes cannot become drug addicts.

What President Gross sought to accomplish was more than getting students to do reading required to pass exams. He hoped that literate non-readers would choose to become voluntary book readers. Although Professor Skinner showed that external reinforcement can teach surprising habits to pigeons and other animals, Dr. Bandura's concept of self-reinforcement shows better how the self-reinforcing power of the human mind explains how the first experience can lead to developing habitual book readers or starting an addiction to opiates. Bandura's insight was to recognize that human beings have a unique power to shape ourselves. In a sense, humans create themselves. 